\title{
Safety and efficacy of directly acting antivirals (sofosbuvir and daclatasvir) in treatment of chronic HCV in HIV-HCV co-infected Egyptian patients
}

\author{
Inas E L-Khedr Mohamed ${ }^{1}$, Kadry Mohamed EL-Saeed ${ }^{1}$, Mahmoud Hassan Al-Sadik ${ }^{2}$ and
}

Christina Alphonse Anwar ${ }^{1 *}$ (D)

\begin{abstract}
Background: Cure of chronic hepatitis $\mathrm{C}(\mathrm{HCV})$ in HIV/HCV co-infected patients is a priority due to their increased risk of complications. Daclatasvir and sofosbuvir treatment regimens with or without ribavirin are considered an important chance for better HCV treatment in patients with HIV/HCV co-infection. This study aimed at the assessment of safety and efficacy of sofosbuvir-daclatasvir treatment regimens in HIV/HCV co-infected Egyptian patients.

Results: Thirty HIV/HCV co-infected adult patients were included. All patients completed the study duration without major problems or drug interactions, HCV PCR was negative for all patients at the end of treatment, yet 12 weeks after ending treatment, only one patient (3.33\%) had HCV relapse.

Liver enzymes showed a significant decrease by the end of treatment and 12 weeks after end of treatment in comparison with their values before treatment $(P$-value $=0.0001)$. CD4 counts as well showed significant increase. There was nonsignificant change in serum albumin, total bilirubin, alfa fetoprotein, complete blood count (CBC), coagulation profile, random blood sugar, or serum creatinine. Ultrasonographic findings did not show significant difference.

Conclusion: Combination of daclatasvir and sofosbuvir have showed $96.67 \%$ sustained virologic response at 12 weeks after treatment (SVR 12) among HIV/HCV co-infected patients, with a good safety profile. Moreover, the treated patients showed a significant increase in CD4 lymphocytic count.
\end{abstract}

Keywords: Sofosbuvir, Daclatasvir, HCV, HIV, SVR

\section{Background}

Five million people are $\mathrm{HIV} / \mathrm{HCV}$ co-infected [1] those are at a higher risk of cirrhosis, hepatocellular carcinoma, hepatic decompensation and death than $\mathrm{HCV}$ mono-infected patients [2]. The widespread use of antiretroviral therapy made HIV as a chronic disease, with significant improvement in acquired immune deficiency syndrome (AIDS) related mortality; however the effect of HIV co-infection on the course of $\mathrm{HCV}$ disease,

\footnotetext{
* Correspondence: christinalfons7@gmail.com

${ }^{1}$ Gastro-enterology and Hepatology Faculty of Medicine, Ain Shams University, Cairo, Egypt

Full list of author information is available at the end of the article
}

although reduced, but still not eliminated by antiretroviral therapy. Moreover, liver-related mortality is the most common cause of death in HIV/HCV co-infected individuals. Therefore, treatment of $\mathrm{HCV}$ infection in $\mathrm{HIV} / \mathrm{HCV}$ co infected individuals is a priority [2].

Treatment of $\mathrm{HCV}$ with interferon-based regimens in $\mathrm{HIV} / \mathrm{HCV}$ co-infected patients was associated with low rates of sustained virologic response, high rates of treatment-related cytopenias, and complex interactions with concomitant antiretroviral drugs [3].

Daclatasvir and sofosbuvir co-administration has pangenotypic anti $\mathrm{HCV}$ effect through inhibition of both NS5A, NS5B proteins, and are safe and effective for 
treatment of chronic hepatitis $\mathrm{C}$ genotype 4 infected patients with minimal adverse events [4]. According to literature, $93 \%$ of $\mathrm{HCV}$ infected patients in Egypt are infected with genotype 4 [5].

Daclatasvir and sofosbuvir have limited pharmacokinetic interactions with antiretroviral drugs, and dose adjustments for daclatasvir in patients receiving moderate inducers or strong inhibitors of cytochrome P450 3A4 are straightforward. Thus, this combination may be valuable for treating patients with $\mathrm{HIV} / \mathrm{HCV}$ co-infection [6].

To our knowledge, safety and efficacy of DAA on Egyptian HIV/HCV co infected patients receiving antiretroviral treatment is not well studied. So we conducted this study aiming at assessing safety and efficacy of daclatasvir plus sofosbuvir regimens in treatment of chronic $\mathrm{HCV}$ in $\mathrm{HIV} / \mathrm{HCV}$ co-infected Egyptian patients.

\section{Methods}

A prospective cohort study has been performed on 30 $\mathrm{HIV} / \mathrm{HCV}$ co-infected adult Egyptian patients receiving treatment at Abbasia Fever Hospital in the period from July 2019 to February 2020.

Included patients were adults (age >18), HCV infected patients (fulfilling NCCVH criteria for DAA treatment protocols) and were already on anti-retroviral drugs for HIV.

The following patients were excluded from the study according to NCCVH protocol: hepatocellular carcinoma, Child C, thrombocytopenic (platelets $<50000$ ), HBsAg positive, Advanced HIV (CD4<200), pregnant, uncontrolled diabetic (HbA1c $>9 \%$ ), end stage renal disease ( Glomerular filtration rate $<30$ ) patients.

Subjected patients were already receiving highly active antiretroviral therapy (HAART), According to AlAbbassia Fever Hospital protocol and Egyptian national guidelines for antiretroviral therapy, December 2017: efavirenz $600 \mathrm{mg}$ one tablet daily + truvada (tenofovir $300 \mathrm{mg}+$ emtricitabine $200 \mathrm{mg}$ ) one tablet daily.

Concerning directly acting anti-viral drug regimen; 25 patients $(83.30 \%)$ were easy to treat according to NCCV $\mathrm{H}$ criteria and received sofosbuvir $(400 \mathrm{mg} /$ day $)+$ daclatasvir $(90 \mathrm{mg} /$ day $)$ for 12 weeks while only 5 patients were considered to be difficult to treat (due to thrombocytopenia, PLT: 50,000-149,000) and received sofosbuvir $(400 \mathrm{mg} /$ day $)+$ daclatasvir $(90 \mathrm{mg} /$ day $)+$ ribavirin $(800 \mathrm{mg} /$ day) for 12 weeks.

All participants were subjected to full history taking, clinical examination, laboratory investigations (including complete blood count $(\mathrm{CBC})$, alanine aminotransferase (ALT), aspartate aminotransferase (AST), serum bilirubin, serum albumin, prothrombin time (PT), international normalized ratio (INR), alfa feto protein (AFP), serum creatinine, random blood sugar, quantitative PCR for HCV and HIV, CD4 T-lymphocyte count) and abdominal ultrasonography .

Patients were under regular follow-up during the study period (before the start of treatment, at the end of treatment and after12 weeks) by clinical examination and laboratory assessment.

Statistical analysis was conducted by using statistical SPSS Package program version 24 for Windows (SPSS, Inc., Chicago, IL) including the mean and standard deviation for all quantitative variables, number and percentage for all qualitative variables, normality test of data using Shapiro-Wilk test was used, Levene's test for testing the homogeneity of variance. Chi-square test ( $x^{2}$ test) , Independent $t$-test to compare two groups for all quantitative variables, one-way analysis of variance (ANOVA-test). Quantitative data was screened, normality test of data using Shapiro-Wilk test was used, Levene's test for testing the homogeneity of variance. All statistical analysis was significant at 0.05 level of probability $(P \leq 0.05)$. Quantitative data was screened, normality test of data using Shapiro-Wilk test was used, Levene's test for testing the homogeneity of variance.

\section{Ethics approval and consent to participate}

This study had been performed in accordance with the ethical standards. Faculty of Medicine, Ain Shams University Ethical Committee approval was taken before starting the study, and the study protocol conforms to the ethical guidelines of the 1975 Declaration of Helsinki. A written consent was obtained from each participant.

\section{Results}

Thirty HIV/HCV co-infected patients, their ages ranged between 21 and 46 years, $80 \%$ of them were males, almost half of the patients were married and $86 \%$ were unemployed. $50 \%$ of them were smokers and IV addicts. All enrolled patients were Child A, all of them completed the study duration without any major problems, quantitative HCV PCR was negative for all patients at the end of treatment, yet 12 weeks after ending treatment only one patient (3.33\%) had HCV relapse.

With regard to route of HIV infection, the commonest was through intravenous drug abuse in $53.3 \%$, different sexual routes in $20 \%$, blood transfusion in $10 \%$, and the rest was not identified.

As regard laboratory data before, after, and 12 weeks of end of treatment, there was no statistically significant differences on comparing values for $\mathrm{CBC}$, coagulation profile, random blood sugar, or serum creatinine.

In addition, Ultrasonographic findings did not show any statistically significant difference throughout the 
study duration (liver parenchyma, portal vein diameter, spleen, ascites, hepatic focal lesions).

On pair-wise comparison, there was a significant decrease in ALT and AST levels by the end of treatment and 12 weeks after treatment in comparison with ALT and AST levels before treatment ( $P$-value: 0.0001$)$. Yet there was non-significant change in serum albumin, total bilirubin, alfa fetoprotein (Table 1).

Difference between CD4 lymphocytic counts before, at the end and 3 months after end of treatment was highly significant $(p$ value $=0.0001)$.

With respect to adverse effects of both drug regimens, fatigue $(73.33 \%)$, headache (46.67\%), insomnia (33.33\%), diarrhea (23.33\%), nausea (20.00\%), and pruritus (13.33\%) were the most commonly documented adverse effects, yet there was no reported severe adverse effects requiring drug discontinuation or hospitalization.

\section{Discussion}

Although effect of HIV co-infection on the course of $\mathrm{HCV}$ disease is reduced but yet not eliminated by antiretroviral therapy and liver-related mortality is still considered the most common cause of death in $\mathrm{HIV} / \mathrm{HCV}$ co-infected individuals [2].

Poor adherence of patients with $\mathrm{HIV} / \mathrm{HCV}$ coinfection receiving $\mathrm{HCV}$ antiviral therapy owing to lots of ongoing challenges was reported by Grebely et al. (2012) [7].

HIV coinfection negatively impacts both sustained virological response and viral kinetics during treatment with pegylated interferon plus ribavirine in subjects infected with HCV genotype 1 or 4 . Yet directly acting antivirals has narrowed the gap in SVR between $\mathrm{HIV} / \mathrm{HCV}$ co-infected and HCV mono-infected persons for most of the used directly acting antiviral drug combinations [8].

Accordingly, treatment of $\mathrm{HCV}$ infection in $\mathrm{HIV} / \mathrm{HCV}$ coinfected individuals is a priority.

In the current study, thirty HIV-HCV coinfected patients with mean age 33.8 years received 12 weeks of daclatasvir plus sofosbuvir with or without ribavirin. $96.67 \%$ of them had a sustained virologic response at week 12 post treatment (SVR 12). This matches with
Wyles et al. (2015) [9] study that revealed SVR rate of 97\% when the same combinations of DAAs were evaluated in patients co-infected with HIV and HCV. Yet our results are higher than the results of Milazzo and his colleges (2017) [10] and Hezode et al. (2016) [11] in their real life studies showing that the SVR 12 in HIV/ $\mathrm{HCV}$ co-infected patients receiving antivirals was about 91\% SVR. This difference may be due to genotypic variance or patient compliance.

In the current study, all patients were receiving antiretroviral combination of truvada (tenofovir+emtricitabine) and efavirenz. As regards drug-drug interactions, there were no drug interactions between DAAs and ARVs. No patient discontinued treatment because of drug-drug interactions. No modifications in HIV therapy were needed with the receipt of daclatasvir or sofosbuvir during treatment in our study and we administered a 90 mg dose of daclatasvir with efavirenz according to Garimella et al. (2016) [12]. This agrees with Panel et al. (2015) [13] who found that both daclatasvir and sofosbuvir have limited pharmacokinetic interactions with other antiretroviral drugs.

As regards achieving SVR on CD4 count, in our study, there was a significant increase in CD4 count in treated patients; Dazley et al. (2015) [14] agreed with our study. This matches with Sarah et al. [15], who documented that the use of DAA therapy in HIV-HCV co-infected patients resulted in a significant increase in CD4 count in patients with pre-DAA CD4 $<350$ cells $/ \mathrm{mm}^{3}$. This can be explained by the persistent immune activation and CD4 $\mathrm{T}$ cell apoptosis involved with $\mathrm{HCV}$ infection in the co-infected patients [16], this activation decreases in response to the success of the HCV treatment (Table 2).

As regards efficacy, a significant decrease in ALT and AST over time in the studied patients 12 weeks after the end of treatment, this agrees with Elsharkawy et al. $(2017)[17,18]$. This came in accordance with one previous study by Mehta et al. in 201 7[19] who studied safety and efficacy of the same regimen in B-Thalassemia major patients with chronic $\mathrm{HCV}$, where responders showed significant improvement in AST and ALT values

Table 1 Comparison of liver function tests findings before, after, and 12 weeks after end of treatment

\begin{tabular}{|c|c|c|c|c|c|}
\hline \multirow[t]{2}{*}{ Items } & \multicolumn{5}{|c|}{ Liver function tests findings (mean \pm SD) } \\
\hline & Alanine amino transferase & Aspartate amino transferase & Serum albumin & Total bilirubin & afetoprotein \\
\hline Before treatment & $54.80 \pm 39.10$ & $52.20 \pm 39.93$ & $4.13 \pm 0.38$ & $0.86 \pm 0.25$ & $7.13 \pm 5.02$ \\
\hline End of treatment & $30.90 \pm 11.91$ & $32.20 \pm 10.31$ & $4.06 \pm 0.290$ & $0.88 \pm 0.27$ & $6.76 \pm 3.42$ \\
\hline SVR at 12 weeks & $28.23 \pm 10.49$ & $30.28 \pm 10.46$ & $4.14 \pm 0.24$ & $0.76 \pm 0.22$ & $6.75 \pm 3.83$ \\
\hline F-value & 10.815 & 7.319 & 0.588 & 1.175 & 0.081 \\
\hline P-value & 0.0001 & 0.001 & 0.557 & 0.180 & 0.923 \\
\hline Significance & $S$ & $S$ & NS & NS & NS \\
\hline
\end{tabular}

SD standard deviation, $P$-value probability, $S$ significant 
Table 2 CD4 lymphocytic level changes before and after treatment

\begin{tabular}{ll}
\hline Items & CD4 lymphocytic count (mean \pm SD) \\
\hline Before treatment & $310.60 \pm 89.9$ \\
End of treatment & $385.90 \pm 108.71$ \\
SVR at 12 weeks & $445.13 \pm 125.44$ \\
F-value & 11.482 \\
$P$-value & 0.0001 \\
Significance & $\mathrm{S}$ \\
\hline SD standard deviation $P$-value probability S significant
\end{tabular}

compared to pretreatment values after 12 weeks of treatment which indicates Sof/Dac role in improving necroinflammation in patients with chronic HCV [19].

Daclatasvir plus sofosbuvir combination regimen was well tolerated with no reported serious adverse events and no discontinuations, The majority of events observed were categorized as mild or moderate as (fatigue $73.33 \%$, headache $46.67 \%$, nausea $20 \%$ and GI upset by 23.33\%). This was similar to what was reported by Sulkowski et al. (2014) [20-22] about safety of DAAs in $\mathrm{HIV} / \mathrm{HCV}$ co-infected patients and what was reported by Wyles et al. (2015) [9] about the safety of daclatasvir plus sofosbuvir combination in co-infected patients.

\section{Limitation}

Our study is limited by the small sample size, short observation period, and that all cases were studied in a single center.

\section{Conclusion}

Combination of daclatasvir and sofosbuvir have showed 96.67\% sustained virologic response at 12 weeks after treatment (SVR 12) among HIV/HCV co-infected patients, with a very good safety profile. Moreover, the treated patients showed a significant increase in CD4 count. Accordingly, HIV/HCV co-infected patients should be treated with sofosbuvir and daclatesvir containing regimens.

\section{Abbreviations \\ HIV: Human immune deficiency virus; HCV: Hepatitis C virus; ALT: Alanine amino tranaminase; AST: Aspartate amino tranaminase; SVR: Sustained virological response; PCR: Polymerase chain reaction; CBC: Complete blood count; CD4: Cluster of differentiation; NS: Non-structural protein; DAA: Directly acting antiviral drugs; NCCVH: National Committee for the Control of Viral Hepatitis; HBsAg: Hepatitis B surface antigen}

\section{Acknowledgements}

Thanks should be applied to Fever hospital staff due to their help in facilitating data collection.

\section{Authors' contributions}

KE: Final approval of the version to be published. IE: Critical revision of the article. MH: Data collection, data analysis, and interpretation. CA: Conception or design of the work and drafting the article. All authors have read and approved the manuscript.
Funding

No funding was obtained for this study

\section{Availability of data and materials}

The datasets and/or analyzed during the current study are available from the corresponding author on reasonable request.

\section{Declarations}

\section{Ethics approval and consent to participate}

This study had been performed in accordance with the ethical standards. Faculty of Medicine, Ain Shams University Ethical Committee approval was taken before starting the study, and the study protocol conforms to the ethical guidelines of the 1975 Declaration of Helsinki. A written consent was obtained from each participant.

\section{Consent for publication}

Not applicable

\section{Competing interests}

The authors declare that they have no competing interests.

\section{Author details}

${ }^{1}$ Gastro-enterology and Hepatology Faculty of Medicine, Ain Shams University, Cairo, Egypt. ${ }^{2}$ Abbassia Fever Hospital, Cairo, Egypt.

Received: 18 January 2021 Accepted: 10 March 2021

Published online: 09 April 2021

\section{References}

1. UNAIDS (2014): Report on the Global AID Epidemic. Retrieved from: http:// www.data.unaids.org/pub/ GlobalReport/2014.

2. Smith CJ, Ryom L, Weber R, Morlat P, Pradier C, Reiss P, Kowalska JD, de Wit S, Law M, el Sadr W, Kirk O, Friis-Moller N, Monforte A'A, Phillips AN, Sabin CA, Lundgren JD (2014) Trends in underlying causes of death in people with HIV from 1999 to 2011 (D: A: D): a multicohort collaboration. The Lancet 384(9939):241-248. https://doi.org/10.1016/S0140-6736(14)60604-8

3. Sulkowski MS, Thomas DL (2003) Hepatitis C in the HIV-infected person. Annals of internal medicine 138(3):197-207. https://doi.org/10.7326/0003-4 819-138-3-200302040-00012

4. Ossama Ashraf Ahmed, Eslam Safwat, Mohamed Omar Khalifa et al., Sofosbuvir Plus Daclatasvir in Treatment of Chronic Hepatitis C Genotype 4 Infection in a Cohort of Egyptian Patients: An Experiment the Size of Egyptian Village. Int J Hepatol. 2018;2018:9616234. doi: 10.1155/2018/ 9616234.

5. Gower E, Estes C, Blach S et al (2014) Global Epidemiology and genotype distribution of the hepatitis C virus infection. J Hepatol 61(1)

6. Bifano M, Hwang C, Oosterhuis B et al (2013) Assessment of pharmacokinetic interactions of the HCV NS5A replication complex inhibitor daclatasvir with antiretroviral agents: ritonavir-boosted atazanavir, efavirenz and tenofovir. Antivir Ther 18(7):931-940

7. Grebely J, Hellard M, Applegate T et al (2012) Virological responses during treatment for recent hepatitis $C$ virus: potential benefit for ribavirin use in HCV/HIV co-infection. AIDS (London, England) 26(13):1653

8. Monje-Agudo A, Castro-Iglesias A, Rivero-Juárez et al (2015) Impact of HIV infection on sustained virological response to treatment against hepatitis $C$ virus with pegylated interferon plus ribavirin. Eurobian J Clin Microbiol Infect Dis:1929-1936

9. Wyles DL, Ruane PJ, Sulkowski MS, Dieterich D, Luetkemeyer A, Morgan TR, Sherman KE, Dretler R, Fishbein D, Gathe JC Jr, Henn S, Hinestrosa F, Huynh C, McDonald C, Mills A, Overton ET, Ramgopal M, Rashbaum B, Ray G, Scarsella A, Yozviak J, McPhee F, Liu Z, Hughes E, Yin PD, Noviello S, Ackerman P (2015) Daclatasvir plus sofosbuvir for HCV in patients coinfected with HIV-1. New England J Med 373(8):714-725. https://doi.org/1 0.1056/NEJMoa1503153

10. Milazzo L, Lai A, Calvi E, Ronzi P, Micheli V, Binda F, Ridolfo AL, Gervasoni C, Galli M, Antinori S, Sollima S (2017) Direct-acting antivirals in hepatitis C virus (HCV)-infected and HCV/HIV-coinfected patients: real-life safety and efficacy. HIV Med 18(4):284-291. https://doi.org/10.1111/hiv.12429

11. Hézode C, Abergel A, Chas J, Conti F, Cotte L, Tateo M, Alric L, Vergniol J, Tomei C, Bernard PH, Loustaud-Ratti V, Arpurt JP, Blaison D, Larrey D, 
Fedchuk L, Bennai Y, Filipovics A, Fontaine H, Pageaux GP (2016) Sustained virologic response to daclatasvir and sofosbuvir, with or without ribavirin, among patients in the French daclatasvir ATU programme infected with HCV genotypes 4, 5 and 6. J Hepatol 64(2):S755. https://doi.org/10.1016/S01 68-8278(16)01471-9

12. Garimella T, You X, Wang R, Huang SP, Kandoussi H, Bifano M, Bertz R, Eley $T$ (2016) A review of daclatasvir drug-drug interactions. Adv Ther 33(11): 1867-1884. https://doi.org/10.1007/s12325-016-0407-5

13. Panel Chung RT, Davis GL, Jensen DM et al (2015) Hepatitis C guidance: AASLD-IDSA recommendations for testing, managing, and treating adults infected with hepatitis C virus. Hepatology 62(3):932-954

14. Dazley J, Sison R, Slim J (2015) Long-Term Consequences of Hepatitis C Viral Clearance on the CD4. AIDS Res Treat 2015:1-4. https://doi.org/10.1155/201 $5 / 687629$

15. Sarah M Michienzi, Jiaqi Cai, Cydnee Harris, et al., HIV-HCV Coinfection: An Investigation of CD4 T-Cell Reconstitution after HCV Direct-Acting Antiviral Treatment. Open Forum Infect Dis. 2019; 6(Suppl 2): S187.Published online 2019 Oct 23. doi: https://doi.org/10.1093/ofid/ofz360.429

16. Braitstein P, Zala C, Yip B, Brinkhof MWG, Moore D, Hogg RS, Montaner JSG (2006) Immunologic response to antiretroviral therapy in hepatitis $C$ viruscoinfected adults in a population-based HIV/AIDS treatment program. J Infect Dis 193(2):259-268. https://doi.org/10.1086/498908

17. Elsharkawy A, Alem SA, Fouad R, el Raziky M, el Akel W, Abdo M, Tantawi O, AbdAllah M, Bourliere M, Esmat G (2017) Changes in liver stiffness measurements and fibrosis scores following sofosbuvir based treatment regimens without interferon. J Gastroenterol Hepatol 32(9):1624-1630. https://doi.org/10.1111/jgh.13758

18. Bachofner JA, Valli PV, Kröger A, Bergamin I, Künzler P, Baserga A, Braun D, Seifert B, Moncsek A, Fehr J, Semela D, Magenta L, Müllhaupt B, Terziroli Beretta-Piccoli B, Mertens JC (2017) Direct antiviral agent treatment of chronic hepatitis $C$ results in rapid regression of transient elastography and fibrosis markers fibrosis-4 score and aspartate aminotransferase platelet ratio index. Liver Int 37(3):369-376. https://doi.org/10.1111/liv.13256

19. Mehta R, Kabrawala M, Nandwani $S$ et al (2017) Safety and efficacy of sofosbuvir and daclatasvir for hepatitis $C$ virus infection in patients with $\beta$ thalassemia major. J Clin Exper Hepatol

20. Sulkowski MS, Gardiner DF, Rodriguez-Torres M, Reddy KR, Hassanein T, Jacobson I, Lawitz E, Lok AS, Hinestrosa F, Thuluvath PJ, Schwartz H, Nelson DR, Everson GT, Eley T, Wind-Rotolo M, Huang SP, Gao M, Hernandez D, McPhee F, Sherman D, Hindes R, Symonds W, Pasquinelli C, Grasela DM (2014) Daclatasvir plus sofosbuvir for previously treated or untreated chronic HCV infection. New England J Med 370(3):211-221. https://doi.org/1 0.1056/NEJMoa1306218

21. Molina J, Chloe O, David Ml et al (2015) Sofosbuvir plus ribavirin for treatment of hepatitis $C$ virus in patients coinfected with HIV (PHOTON-2): a multicentre, open-label, non-randomised, phase 3 study. The Lancet 385(9973):1098-1106. https://doi.org/10.1016/S0140-6736(14)62483-1

22. Naggie S, Cooper C, Saag M, Workowski K, Ruane P, Towner WJ, Marks K, Luetkemeyer A, Baden RP, Sax PE, Gane E, Santana-Bagur J, Stamm LM, Yang JC, German P, Dvory-Sobol H, Ni L, Pang PS, McHutchison J, Stedman CA, Morales-Ramirez JO, Bräu N, Jayaweera D, Colson AE, Tebas P, Wong DK, Dieterich D, Sulkowski M, ION-4 Investigators (2015) Ledipasvir and sofosbuvir for HCV in patients coinfected with HIV1. New England J Med 373(8):705-713. https://doi.org/10.1056/NEJMoa1501315

\section{Publisher's Note}

Springer Nature remains neutral with regard to jurisdictional claims in published maps and institutional affiliations.

\section{Submit your manuscript to a SpringerOpen ${ }^{\circ}$ journal and benefit from:}

- Convenient online submission

- Rigorous peer review

- Open access: articles freely available online

- High visibility within the field

- Retaining the copyright to your article

Submit your next manuscript at $\boldsymbol{\nabla}$ springeropen.com 